\title{
Anxiety in EFL Listening Comprehension
}

\author{
Fang Xu \\ The School of Foreign Languages, Qingdao University of Science and Technology, Qingdao, China \\ Email: sailqd_2008@163.com
}

\begin{abstract}
The anxiety for EFL learners that accompanies the listening comprehension (LC) task is difficult to detect, but potentially one of the most debilitating, because in order to interact verbally the listener must first understand what is being said. With the instructional emphasis on input processing, LC anxiety merits closer examination. By elaborating the definition and process of listening comprehension, this paper analyzes the anxiety in listening comprehension in detail and discusses the pedagogical implications that might help instructors address LC anxiety in their foreign language (FL) classroom.
\end{abstract}

Index Terms - listening comprehension, anxiety, short-term memory, long-term memory

\section{INTRODUCTION}

For the most EFL (English as a foreign language) learners, listening is the most difficult one among the four skills. Research shows that in order to be effective listeners, learners must be able to actively and strategically participate in the listening process within a low-anxiety classroom environment. Recognizing the effect of anxiety on listening is the first step; the next is to find out the sources of LC anxiety and propose solutions.

This paper analyzes the relationship between anxiety and listening comprehension in detail. The aim of this paper is to present the sources and solutions to LC anxiety as reported by foreign language students and discusses the pedagogical implications that relate to the results.

\section{LITERATURE REVIEW}

Anxiety

Anxiety is quite possibly the affective factor that most pervasively obstructs the learning process. It is associated with negative feelings such as uneasiness, frustration, self-doubt, apprehension and tension. Heron (1989: 33) makes reference to what he terms existential anxiety, which arises out of a group situation and has three interconnected components that are relevant to the language classroom: 'Acceptance anxiety. Will I be accepted, liked, wanted? Orientation anxiety. Will I understand what is going on? Performance anxiety. Will I be able to do what I have come to learn?'

For acquisition to take place, the learner has to be able to absorb the appropriate parts of the input. There can be 'a mental block that prevents acquirers from fully utilizing the comprehensible input they receive for language acquisition' (Krashen, 1985, p.3). This block, called 'the affective filter', might be because 'the acquirer is unmotivated, lacking in self-confidence, or anxious' (Krashen, 1985, p.3). The Affective Filter Hypothesis ascribes variation between learners to their psychological states. If the filter is 'up', comprehensible input cannot get through; if it is 'down', they can make effective use of it. In particular the reason why younger learners are better at L2 acquisition over the long term is that 'the affective filter gains dramatically in strength at around puberty' (Krashen, 1985, p.13). Older learners are cut off from proper access to comprehensible input by the increased strength of the filter. In Krashen's words, 'comprehensible input and the strength of the filter are the true causes of second language acquisition' (Krashen, 1982, p.33), one positively, one negatively.

There are few, if any, disciplines in the curriculum which lay themselves open to anxiety production more than foreign or second language learning. There is a great deal of vulnerability involved in trying to express oneself before others in a shaky linguistic vehicle. It is possible in some cases that the methodology used can contribute to furthering anxiety. With the grammar-translation method one might assume a reduction of the possibility of anxiety, since the learners have relatively little of themselves invested in the activities required. However, with the advent of methods which focus on communication, and especially communication involving more personal aspects of one's being, such as feelings, if care is not taken to provide an emotionally safe atmosphere, the chance for the development of anxiety-provoking situations can increase greatly. This is particularly true if at the same time the stakes involved are very high, such as academic settings, where the evaluation of the learner can conceivably have far-reaching consequences.

When anxiety is present in the classroom, there is a down-spiralling effect. Anxiety makes us nervous and afraid and thus contributes to poor performance; this in turn creates more anxiety and even worse performance. The feelings of fear and nervousness are intimately connected to the cognitive side of anxiety, which is worry. Worry wastes energy that should be used for memory and processing on a type of thinking which in no way facilitates the task at hand (Eysenck 1979). Although it is a major obstacle to language learning, anxiety can be reduced. 
Learners may suffer from anxiety in relation to a number of aspects of the teaching-1earning process; for example, about the language itself, about speaking in front of other learners, about the language class, about the behaviour of their peers, about their standing in the competition with fellow learners, about taking tests, about the speakers of the language they are learning, etc. The more anxious they are, the less well they believe they can perform.

Classroom anxiety became extreme for the student with the lowest proficiency. Each class presented new challenges and the anxiety seemed to be debilitating. It is helpful for teachers to understand the pressures felt by learners in the classrooms. Foss and Reitzel suggested that knowledge and skills can best be dealt with through role play, drama, and oral interpretation. Through performing the works of others, thoroughly rehearsed in terms of both verbal and non-verbal language, the students experience less communication anxiety than if they themselves must generate their own target language utterances.

\section{Harmful anxiety}

Though some language researchers assert that a positive mode of anxiety exists, most language research shows a negative relationship between anxiety and performance. The negative kind of anxiety is sometimes called 'debilitating anxiety' because it harms learners' performance in many ways, both indirectly through worry and self-doubt and directly by reducing participation and creating overt avoidance of the language. Harmful anxiety can be related to plummeting motivation, negative attitudes and beliefs, and language performance difficulties. Gardner and MacIntyre stated that the strongest (negative) correlate of language achievement is anxiety (1993).

\section{Helpful anxiety}

Some research suggested that language anxiety was actually 'helpful' or 'facilitating' in some ways, such as keeping students alert (Scovel 1978). Helpful anxiety has been shown in a few studies to be related to:

- high language proficiency and self-confidence among a hand-picked group of excellent language learners (Ehrman and Oxford 1995);

- oral production of difficult English structures among native Arabic-speakers and Spanish-speakers (Kleinmann 1977);

- good grades in language classes for students in regular French, German, and Spanish classes but not for students in audiolingual classes (Chastain 1975).

\section{Anxiety in listening comprehension}

Research in foreign or second language learning has begun to show that anxiety directly undermines motivation and creates a negative affective response to the foreign language being studied (Gardner et al. 1987). Therefore, addressing foreign language listening comprehension anxiety is fast becoming a priority in the classroom.

In most of the literature on language leaning anxiety, students have reported that speaking in the foreign language produces the most anxiety (Young 1990; Phillips 1992). Slowly within the studies of speaking anxiety, listening comprehension (LC) anxiety has begun to surface as a problematic area for students. Krashen (in Young 1992) acknowledged that, although speaking is cited as the most anxiety-producing skill, LC is also "highly anxiety provoking if it is incomprehensible" (168).

According to Scarcella and Oxford (1992), listening anxiety occurs when students feel they are faced with a task that is too difficult or unfamiliar to them. This anxiety is exacerbated if the 1isteners are under the false impression that they must understand every word they hear. Many learners believe that in order to be "good at a language they need perfect pronunciation, massive amounts of vocabulary, extensive grammar knowledge, overseas experience, and a natural aptitude for language before they even open their mouths (Horwitz1987). As a result, the anxiety that arises during the listening process often springs form what Joiner (1986) calls a negative "listening self-concept," that is, a low level of self-confidence in the area of listening.

Gardner and MacIntyre (1993) show that the most negative element that influences the language performance is anxiety.

The anxiety that accompanies the LC task is the one that is most easily ignored because the goal of most classroom activities focuses on the speaking skill. When considered a stepping-stone to speaking, LC is more often than not treated as a passive skill that will "happen" during the regular classroom activities. With speaking, teachers anticipate anxiety on the part of the students and expect them to stumble and hesitate. To remedy the situation, teachers engage in all kinds of structured practice designed to help the students overcome their fear of speaking. LC anxiety can undermine speech production because, in order to interact verbally, the listener must first understand what is being said. Therefore, LC anxiety should not be ignored, but actively addressed.

\section{RESEARCH METHODOLOGY}

\section{A. Subjects}

The participants in this study were 140 non-English majors placed into two classes, from Qingdao University of Science and Technology. The subjects had nearly the same experience in English learning. They had had six years of English learning experience in the secondary school and were in the second term of their freshman period at the time when this study was conducted. They were all students of engineering, and were offered the same courses. In addition, they used the same textbooks. Therefore, they shared the same environment and experience, and their ages were nearly 
the same, ranging from 18 to 22 .

\section{B. The Study}

The purpose of the study was to report descriptive research, rather than inferential or quantitative research; therefore the questionnaire was distributed immediately after the LC part of the exam, so that the likelihood of the students experiencing LC anxiety was high, and there was a 100 percent return of responses. The participants were asked to complete a questionnaire (see Appendix A) that elicited the following information: (1) whether they were experiencing listening anxiety or not; (2) if they did, what made them anxious when participating in a LC exercise; and (3) what types of settings, exercises, or activities helped to lower their anxiety level. Of the 140 participants, only nine percent reported that they did not experience LC anxiety. The size of this number emphasizes the need to address directly the LC anxiety experienced by the other 91 percent of the students.

The 140 questionnaires generated 200 responses addressing sources of anxiety (see Table 1), and 170 suggestions on ways to alleviate LC anxiety (see Table 2). The analysis of the questionnaire consisted of two parts: (1) analysis of students' responses about sources of LC anxiety and (2) examination of suggestions for reducing LC anxiety. In determining sources of LC anxiety, students' comments clustered around the following four general categories:

a) LC anxiety associated with characteristics of FL input;

b) LC anxiety associated with processing-related aspects of FL;

c) LC anxiety associated with instructional factors; and

d) LC anxiety associated with attributes of the teacher or learner.

TABLE 1

STUDENTS' REPORTED SOURCES OF LC ANXIETY (N=200)

\begin{tabular}{|c|c|c|}
\hline Category & Sources & $\%$ of responses \\
\hline \multirow[t]{6}{*}{ Input } & Nature of the speech & $27 \%$ \\
\hline & Level of difficulty & $10 \%$ \\
\hline & Lack of clarity & $6 \%$ \\
\hline & Lack of visual support & $3 \%$ \\
\hline & Repetition of input & $2 \%$ \\
\hline & Total & $48 \%$ \\
\hline \multirow[t]{5}{*}{ Process } & Inappropriate strategies & $23 \%$ \\
\hline & Lack of time to process & $2 \%$ \\
\hline & Can't "study" for LC & $2 \%$ \\
\hline & Can't check answers & $2 \%$ \\
\hline & Total & $29 \%$ \\
\hline \multirow[t]{4}{*}{ Instructional Factors } & Lack of LC practice & $3 \%$ \\
\hline & "The test thing" & $3 \%$ \\
\hline & Uncomfortable environment & $2 \%$ \\
\hline & Total & $8 \%$ \\
\hline \multirow[t]{4}{*}{ Personal Factors } & Fear of failure & $9 \%$ \\
\hline & Nerves & $5 \%$ \\
\hline & Instructor's personality & $1 \%$ \\
\hline & Total & $15 \%$ \\
\hline \multicolumn{3}{|c|}{ TABLE 2} \\
\hline \multicolumn{3}{|c|}{ STUDENTS’ SUGGESTIONS FOR ALLEVIATING LC ANXIETY (N=170) } \\
\hline Category & Suggestion & $\%$ of responses \\
\hline \multirow[t]{4}{*}{ Input } & Make input comprehensible & $17 \%$ \\
\hline & Use variety of input & $7 \%$ \\
\hline & Structure tasks & $6 \%$ \\
\hline & Total & $30 \%$ \\
\hline \multirow[t]{3}{*}{ Process } & Focus on strategies needed & $2 \%$ \\
\hline & Notetaking / use of Chinese & $2 \%$ \\
\hline & Total & $4 \%$ \\
\hline \multirow[t]{5}{*}{ Instructional Factors } & Increase class time for $\mathrm{LC}$ & $40 \%$ \\
\hline & Combine LC with other skills & $15 \%$ \\
\hline & Provide regular feedback & $3 \%$ \\
\hline & Create out-of-class opportunities & $3 \%$ \\
\hline & Total & $61 \%$ \\
\hline \multirow[t]{3}{*}{ Personal Factors } & Experience small successes & $3 \%$ \\
\hline & Meditation / breathing, etc. & $2 \%$ \\
\hline & Total & $5 \%$ \\
\hline
\end{tabular}

Within each of the categories above, student responses fell into several subcategories. These responses were summarized by percentages under each category (see Table 1 and Table 2 for these summaries). Appendix B documents 
a sample of comments students made about each of the reported sources of LC anxiety. Selection of the sample comments was made by the author and was based on the author's subjective opinion of which comments would be most informative to the foreign language teacher.

\section{The Results}

The results of the study will be discussed by first presenting the sources of anxiety reported by the students, based on the four major categories and the subcategories. The students' suggestions for reducing LC anxiety are presented in conjunction with the reported source of anxiety. The final section consists of a brief discussion of the pedagogical implications based on the results of the study.

\section{LC Anxiety Associated with Characteristics of Input}

Forty-eight percent of the students' responses focused on some characteristic of input as being a source of LC anxiety.

Nature of the speech. Of the 27 percent that reported the nature of speech as a source of anxiety, 22 percent reported that speech that was too fast created the most anxiety. The other five percent claimed poor enunciation, different accents, and teachers, that spoke too softly as sources of anxiety.

Level of difficulty. Students expressed anxiety and frustration with LC exercises that were too difficult. Students associated the level of difficulty of input in terms of the use of vocabulary that was unfamiliar or beyond the level of the student, the use of complicated syntax, and the use of texts based on unfamiliar topics.

Lack of clarity. The students reported feeling anxious when they did not know what kind of text they were listening to, why they were listening to it, what they were supposed to be listening for, and what they were supposed to do once they were through listening. Although the students' comments were geared toward often-confusing directions provided by the teacher, Lund (1990) pointed out that the issue of text difficulty that stems from the nature of the text itself (e.g., authentic vs. edited) can impact the listeners' orientation to the text, and, ultimately, their comprehension of the text.

Lack of visual support. Although mentioned as a source of anxiety by only a small number of students, some learners felt as if they lacked the footing necessary to even make an educated guess without some type of visual input.

Lack of repetition. Students expressed frustration toward the traditional approach to LC practice where input is presented only twice. This feeling was especially strong in a testing situation where the student must decipher the question to be answered, then come up with, or select, the correct response. Anxiety was associated with the "two strikes and you're out" approach to LC tasks.

\section{Suggestions for reducing LC Anxiety Associated with Input Characteristics}

Thirty percent of students' suggestions for reducing LC anxiety focused on input-related variables.

Make input comprehensible. Many students (17 percent) felt that input would be more comprehensible to them if it were based on familiar, meaningful topics and vocabulary. Many suggested alleviating anxiety by making the input more informal, and ungraded, rather than formal, graded activities. In other words, students wanted to practice LC, but did not want to be graded each time they practiced it. Others felt that dictation and translation exercises would make input more comprehensible.

Use variety of input. Numerous students suggested incorporating games and other fun activities into the classroom as the vehicle for listening activities. Their suggestions for activities included the following:

(a) "use smaller group activities and less formalized English on topics more exciting to students";

(b) "have English-speaking people, other than our own professor, occasionally speaking English to the class";

(c) "practice with listening without watching, such as hearing music in English from a tape or the radio";

(d) "talk more interactively in groups"; and

(e) "hear the students' cassette tapes in class."

Structure tasks. The students in this study wanted to know what they were doing. They felt that clear instructions, advanced organizers, and structured tasks would alleviate some anxiety because they would know where to begin and in what direction to go. A few students offered possible ways of structuring LC activities:

(a) "have a person speaking in English while the class writes down in Chinese and in English what the person said. Then review the different responses";

(b) "someone could speak all class period and we could each try to write down what we hear, then compare weaknesses. Maybe there are some common ones that could be cleaned up";

(c) "have more actual test situation practice because it's very different from in-class listening with stress on the important words and numerous repetitions until we figure it out";

(d) "repeat the passage, repeat the passage, repeat the passage."

In sum, for these students, LC anxiety stemmed form certain characteristics of the input (unfamiliar or difficult text, unclear directions, no visual support) and specific features of the delivery of the input (too fast, poor enunciation, lack of time or repetitions to process information, minimal practice and feedback). To minimize LC anxiety associated with input, students suggested, in essence, making input comprehensible using a variety of input for LC activities, structuring the LC tasks with clear instructions, and offering a specific purpose for the task.

\section{LC Anxiety Associated with Process-Related Aspects of LC}

Twenty-nine percent of student responses commented on process-related aspects of FL learning as a source of LC anxiety. 
Inappropriate strategies. A review of students' comments indicates that many saw comprehension as the process of understanding or translating every word, as opposed to understanding the message. Students reported feeling anxious when they try to translate one part of what they hear and then miss the next part. If students perceive LC as word-for-word decoding, frustration and anxiety become a regular part of the LC process.

Some students feared that they would not "understand" contextually what they were listening to, or that they would miss key words. Other students feared they would hear the "wrong thing" and assume that the text was about one topic when it is actually about something else. Others mentioned having weak spelling and retention skills.

Lack of processing time. Some students reported feeling anxious when asked to respond immediately to the listening text and the teacher did not allow them enough time to process the information in the text or the questions about the text.

Can't study LC. Several students stated that, unlike a test on grammar, it was difficult to study for a LC test. They expressed frustration at not knowing exactly what or how to prepare.

Can't check answers. Students reported feeling anxious about LC tasks because, unlike reading comprehension, LC is a "one-shot deal".

\section{Suggestion for Reducing LC Anxiety Associated with Process-Related Aspects of LC}

The low percentage (four percent) of suggestions under this category indicates that perhaps students are not sure of how to decrease their anxiety in these instances. In other words, perhaps they are unsure of what it means to be a strategic listener.

Focus on the strategies needed. At least some of the students in this study knew that knowledge about effective strategies could increase their LC abilities and reduce their LC anxiety. They suggested that the teacher "help the students to be able to be aware of their skills."

Notetaking / use of Chinese. Many students felt that they end up being evaluated on "the language they produced in the answer rather than their comprehension" of the text. Taking notes while listening was considered effective for some, while others felt that being able to answer questions in Chinese would counterbalance the anxiety they experienced when they lacked adequate target language to express what they actually comprehended. A study done by Lee (1986) supports the use of native language to test reading comprehension. Lee observed that "recall protocols written in the subjects' native language contained statistically significantly more of the passage than recall protocols written in the subjects' target language" (350). Applicability to LC would seem plausible, although not yet proven.

Some students wanted to hear more Chinese from the instructor and suggested that "when speaking English they [the instructors] translate into Chinese sometimes, especially with common phrases."

In sum, students reported LC anxiety associated with this category as not having enough time to process input, not using appropriate LC strategies to understand input, not knowing how to prepare for a LC test, and not knowing how to confirm whether what they understood was accurate or not.

In terms of suggestions, students reported that their LC anxiety would decrease if the teacher would train them to use LC strategies, if they could take notes during a LC task, and if their comprehension skills were evaluated on the basis of their native language, not the FL. In addition, some students felt they would benefit from having the teacher translate more into Chinese.

\section{Listening Comprehension Anxiety Associated with Instructional Factors}

This category surfaced as the least-reported source of anxiety ( 8 percent), but paradoxically was the category that comprised 61 percent of the students' suggestions for alleviating LC anxiety.

Lack of LC practice. Students reported feeling anxious when little or no class time had been devoted specifically to LC practice, which left them "feeling incompetent and unprepared."

"The test thing." Some students reported becoming anxious just because it is a test, rather than an activity-perhaps because under test conditions, they cannot replay the LC passage as many times as they need, and they are not able to go back to the question when read aloud.

Uncomfortable environment. Students reported that their physical surroundings, such as a room being too hot or too cold, were important and often interfered with LC. Others reported becoming anxious if the room is too noisy, lacks oxygen, or is small and cramped.

Suggestions for Reducing LC Anxiety Associated with Instructional Factors

A majority (61 percent) of the suggestions students offered focused on instructional factors.

Increase class time for LC practice. To develop the listening skill, many students stated that there must be "more class activities that focus specifically on the LC skill."

Receive regular feedback. The students in this study expressed a need to know if they understood correctly or not. Most agreed that the more immediate the feedback, the better.

Combine LC with other skills. Students referred specifically to combining listening with reading, that is, combining auditory input with written input. Their comments included these examples:

1. "Have someone say the words as I'm reading / looking at it."

2. "Practice reading out loud in class would help my pronunciation and listening skill."

3. "It would help to be able to read it as I was going along."

Create out-of-class opportunities. Having informal, social interactions with native speakers was reported as a way in 
which students could experiment with the language in a non-threatening situation. They suggested bringing native speakers into the classroom so they could feel more confident about approaching native speakers outside the classroom.

In sum, students associated LC anxiety with a lack of LC practice, LC tests, and lack of a comfortable physical environment. To reduce their LC anxiety, they suggested having more LC practice in class, receiving feedback about their LC skills regularly, combining LC with other skills, and having opportunities to listen to native speakers and not just their FL teachers.

\section{LC Anxiety Associated with Personal Attributes of Teacher and Learner}

Fifteen percent of the students' comments focused on personal and interpersonal attributes as sources of LC anxiety.

Fear of failure / nerves. Many students walk into a FL classroom feeling nervous and fearing failure or ostracism. This emotional state of mind might stem from a negative past experience or from the belief that they lack the prerequisites necessary to be a "good" language learner.

Instructor's personality. Although few, the responses in this category were insightful. They reported experiencing LC anxiety when teachers had unrealistic expectations, that is, when they expected everything to be perfect and were critical when students did not answer correctly. Teachers that were inaccessible and "don't show any reaction to your performance" also inspired anxiety in their students. One student referred to a "hostile" environment created by personality clashes between students, or between students and teacher. In shot, instructors that put students on the spot press for answers, and openly demonstrate frustration when the correct answer is not forthcoming create anxiety.

\section{Suggestions for reducing LC Anxiety Associated with Personal Attributes of teacher and learners}

Only five percent of the responses fell within this category.

Experience small successes. One student reported being able to "develop language confidence" in LC by experiencing small successes. Another stated that "the more I understand, the less anxious I am."

Using anxiety-reducing techniques. Many students reported using meditation, breathing exercises, or "self-affirmations" to reduce LC anxiety. Others found that "thinking about something less stressful was useful." One student reported resorting to "prayer."

In sum, students reported LC anxiety due to variables like learner self-confidence and instructor's "harsh" teaching manners. To reduce LC anxiety, they suggest developing language confidence through small successes and through the use of anxiety-reducing techniques.

\section{Pedagogical Implications}

1) Make input comprehensible.

A listener who has experienced success in simple comprehension tasks is more likely to have the necessary self-confidence to adopt these active listening tactics. In contrast, if learners have been exposed to listening materials that are so difficult as to be incomprehensible, they suffer in two ways: not only is the whole experience a dispiriting one, but it is also likely to encourage passive and unsuccessful listening habits where the learners equate 'listening' with sitting back and letting a largely meaningless sequence of sounds wash over them.

Effective listeners seemed to be aware when they stopped attending and made an effort to redirect their attention to the task and ineffective listeners, when faced with loss of comprehension, they usually just stopped listening or failed to be aware or their inattention. The relationship between self-confidence and performance is also reflected in the results of a study by Fujita (1984), who found that self-confidence was considered one of the major factors affecting the LC ability of successful students.

2) Select material of appropriate interest 1 evel.

Students perform better with material they want to listen to because they enjoy it. Apart from catering for any specialist interests you may know about, you should find the following generally useful: jokes, personal anecdotes, human interest stories, material containing some puzzle to be solved, and serialised stories.

3) Use your prior knowledge of the material to guide the listeners.

This may be done in two ways:

a) You can introduce the topic with a short discussion; for example you could announce the title or say the first sentence and ask what they think it will be about. This arouses certain expectations and makes the students mentally prepared for the topic; it may also activate latent knowledge of vocabulary associated with the topic.

b) Perhaps most important of all, you can help students to be selective by giving them a purpose for listening. Give a few questions before the first hearing, or ask them to pick out the 3 main points, or the main steps in a process. Set tasks which entail concentrating on certain features and filtering out irrelevant information.

4) Select material at an appropriate level of linguistic difficulty as regards syntax and vocabulary.

5) Control the length of the material.

Listening exercises should be shorter than reading texts, especially in the earlier stages. If you want to use a longer exercise, split it up into short sections and ask questions appropriate to each short section as you go along.

6) Repeat the material.

This is obvious but needs to be done with care. In most target situations material will be heard only once. It is, therefore, a good idea to give students something specific to listen for, even on first hearing to prove that they can get some information from a single hearing. It is amazing how often students are prepared to listen to the same thing over 
and over again provided that they are given a good reason for doing so, like trying to answer specific questions or solving some sort of problem.

Listeners at lower levels of proficiency seem to find that a simple repetition of a noun phrase is the easiest to comprehend; more advanced learners can cope with both pronouns and varied nouns descriptions (Chaudron 1983)

7) Control the speed of delivery and clarity of diction.

This again is obvious but it is very easy to take it too far. Students who will eventually have to listen to speech at full speed and with native speaker fluency (with short forms, unstressed words, etc) should be weaned off careful, slow speech as quickly as possible. Another important reason for not going too slowly is that in very slow speech the useful cues to grammatical relationships provided by intonation are obscured, and extremely slow speech actually places a greater burden on the STM because by the time the voice reaches the end of a sentence the learner may have forgotten how it started. If you want to make things easier in the early stages by controlling speed, it is better to deliver each sentence at a moderate speed but pause rather longer than you normally would, between sentences. This gives the listener a little more time to process the information without distorting the normal speech patterns.

8) Be understanding and sensitive to student fears about LC and FL learning.

According to McKeachie (1994), an important instructor characteristic that can go a long way in relieving personal anxiety is a sympathetic attitude towards the problems and fears of the students. An important step, therefore, is to create a positive, non-threatening atmosphere within the classroom. The climate of the classroom is directly related to the attitudes, expectations, and physical presence of the instructor, which, in turn, determine the way in which the instructor and students interact. If we want students to experience success in FL learning, we must not ignore their beliefs, perceptions, fears, obstacles and anxieties.

One way to expose students' fears about FL learning, and LC in particular, would be to have them list the sources of LC anxiety on the board. Students would see that listening anxiety is shared by nearly everyone and that most of the other students experience similar fears of failure. Knowing that others share their beliefs can motivate the students to overcome their own anxiety.

\section{CONCLusion}

Anxiety is the important factor that affects the LC ability of successful students. We should decrease listening comprehension anxiety by increasing self-confidence in the FL classroom. Listening comprehension activities that address listening anxiety will empower both the teacher and the learner. When teachers and students make the shift from listening for correctness to listening for a message, the motivation to understand increases and the fear of being "wrong" decreases. Learners that are motivated to listen and learn will have positive attitudes toward the target language and its speakers.

\section{APPENDIX A LiSTENING COMPREHENSION ANXIETy QUESTIONNAIRE}

This questionnaire is part of a research project that will provide important information about how instructors can help lower the anxiety level of language learners when doing listening comprehension tasks. Thank you for your participation.

Please answer as specifically as possible.

1. Do you experience anxiety when you are participating in listening comprehension activity?

$$
\square \text { Yes } \square \text { No }
$$

2. What makes you anxious when you are participating in a listening comprehension activity?

3. What types of exercises, settings, or activities help to lower your anxiety level?

\section{APPENDIX B STUDENT COMMENTS By CATEGORY AND SUBCATEGORY}

\section{LC Anxiety Associated with Characteristics of Input}

Nature of the speech.

"The teacher speaks too fast and I'm afraid I can't understand it."

"I am afraid if the teacher speaks too quickly, there is not enough time to translate in my mind and write down."

Level of difficulty.

"I don't understand the words the teacher uses."

"I have never heard the words the teacher uses before."

"I am anxious that I will not understand the topic."

Lack of visual support.

"I could recognize the words written but not orally."

"See the English film with English subtitles."

Lack of repetition.

"I hope the teacher speaks her words twice or three times."

The teacher should repeat her words."

LC Anxiety Associated with Process-related Aspects of LC 
Inappropriate strategies.

"I am afraid that I don't have good listening skill to listen and write."

"In order to understand one word of a sentence, I miss the rest part of the whole sentence."

"I try to understand every word, but I don't know which is a key word or most important."

Lack of time to process the input.

"I don't have time to think about what the teacher speak to me."

"I feel anxious and unable to answer the teacher's question when the teacher speaks in a louder voice to repeat."

Can't study LC.

"I don't know how to preview and review LC."

"I don't know how to prepare for LC exams."

Can't check answers.

"I feel anxious when I practice LC because I don't know how to check my answers."

"Listening is not like reading because I can't go back to the previous materials if I can't understand."

\section{LC Anxiety Associated with Instructional Factors}

Lack of LC practice

"I feel anxious because there is no LC practice in class."

"The test thing"

"I feel nervous because it is a test."

Uncomfortable environment

"The classroom is too dark so I feel uncomfortable."

"The classroom is very hot. We need cool breeze to make us feel relaxed."

"I feel nervous because there are too many students in the classroom."

\section{LC Anxiety Associated with Personal Attributes of Teacher and Learner}

Fear of failure/ nerves.

"I am afraid of losing face in the public so I feel nervous when the teacher asks me to answer questions."

"I hope the teacher doesn't ask one person to answer question but ask the whole class to answer her question."

Instructor's personality

"My English teacher likes to praise me in the class when I answer the question correctly, which makes me feel confident."

"I feel nervous when I make mistakes in answering questions and some classmates laugh at me loudly."

"I feel anxious when the teacher doesn't show any reaction to my performance."

\section{REFERENCES}

[1] Chastain, K. (1975). Affective and ability factors in second language learning. Language Learning, 25, 153-161.

[2] Chaudron, C. (1983). "Simplification of input: topic reinstatements and their effects on L2 learners' recognition and recall." TESOL Quarterly 17/3:437-58.

[3] Ehrman M. and R. Oxford. (1990). Adult Language learning styles and strategies in an intensive training setting. Modern Language Journal, 74, 3, 311-327.

[4] Ehrman M. and R. Oxford. (1995). Cognition plus: Correlates of adult language proficiency. Modern Language Journal, 79, 67-89.

[5] Eysenck, M. W. (1979). Anxiety, learning and memory: A reconceptualization. Journal of Research in Personality, 13, $363-385$.

[6] Gardner, R. C., R. N. Lalande, R. Moorcroft, and F. T. Evers. (1987). "Second Language Attrition: The Role of Motivation and Use.” Journal of Language and Social Psychology 6: 173-80.

[7] Gardner, R. C. and P. D. MacIntyre. (1993). On the measurement of affective variables in second language learning. Language Learning, 43, 157-194.

[8] Heron, J. (1989). The facilitator's Handbook. London: Kogan Page.

[9] Heron, J. (1990). Helping the Client. London: Sage.

[10] Heron, J. (1992). Feeling and Personhood: Psychology in Another Key. London: Sage.

[11] Horwitz, Elaine K. (1987). "Surveying Student Belief About Language Learning," 119-129 in Anita Wenden and Joan Rubin, eds., Learning Strategies in Language Learning. Englewood Cliffs, NJ: Prentice Hall.

[12] Joiner, Elizabeth. (1986). "Listening in the Foreign Language," 43-70 in B. H. Wing, ed., Listening Reading, and Writing: Analysis and Application. Middlebury, VT: Northeast Conference on the Teaching of Foreign Languages.

[13] Kleinmann, H. (1977). Avoidance behavior in adult second language acquisition. Language Learning, 27, 93-107.

[14] Krashen, S. D. (1982). Principles and Practice in Second Language Acquisition. Oxford: Pergamon Press.

[15] Krashen, S. D. (1985). The Input Hypothesis: Issues and Implications. London: Longman.

[16] Phillips, Elaine. (1992). "The Effects of Language Anxiety on Students' Oral Test Performance and Attitudes." The Modern Language Journal 76, 1: 14-26

[17] Scarcella, Robin C., and Rebecca L. Oxford. (1992). The Tapestry of Language Learning: The Individual in the Communicative Classroom. Boston: Heinle \& Heinle.

[18] Scovel, T. (1978). The effect of affect on foreign language learning: A review of the anxiety research. Language Learning, 28, 129-142.

[19] Young, Dolly Jesuita. (1990). “An Investigation of Students' Perspective on Anxiety and Speaking." Foreign Language Annals 23, 6: 539-553. 
[20] Young, Dolly Jesuita. (1991). "Creating a Low Anxiety Classroom Environment: What Does Language Anxiety Research Suggest?" Modern Language Journal 75, 4: 426-437.

[21] Young, Dolly Jesuita. (1992). "Language Anxiety from the Foreign Language Specialist's Perspective: Interviews with Krashen, Omaggio Hadley, Terrell, and Rardin.” Foreign Language Annals 25, 2: 157-172.

Fang Xu was born in Qingdao, China in 1970. She received her M.A. degree in linguistics from PLA University of Foreign Languages, China in 2004.

She is currently a lecturer in the School of Foreign Languages, Qingdao University of Science and Technology, Qingdao, China. Her research interests include psycholinguistics and American literature.

Ms. Xu's paper "Short-Term Memory, Listening Comprehension and Input Hypothesis" won the third prize from China English Language Education Association. 